Document downloaded from:

http://hdl.handle.net/10251/81007

This paper must be cited as:

Mateos Ronco, AM.; Hernandez Mezquida, JM. (2016). Developing a performance management model for the implementation of TQM practices in public education centres. Total Quality Management and Business Excellence. 1-33. doi:10.1080/14783363.2016.1216309

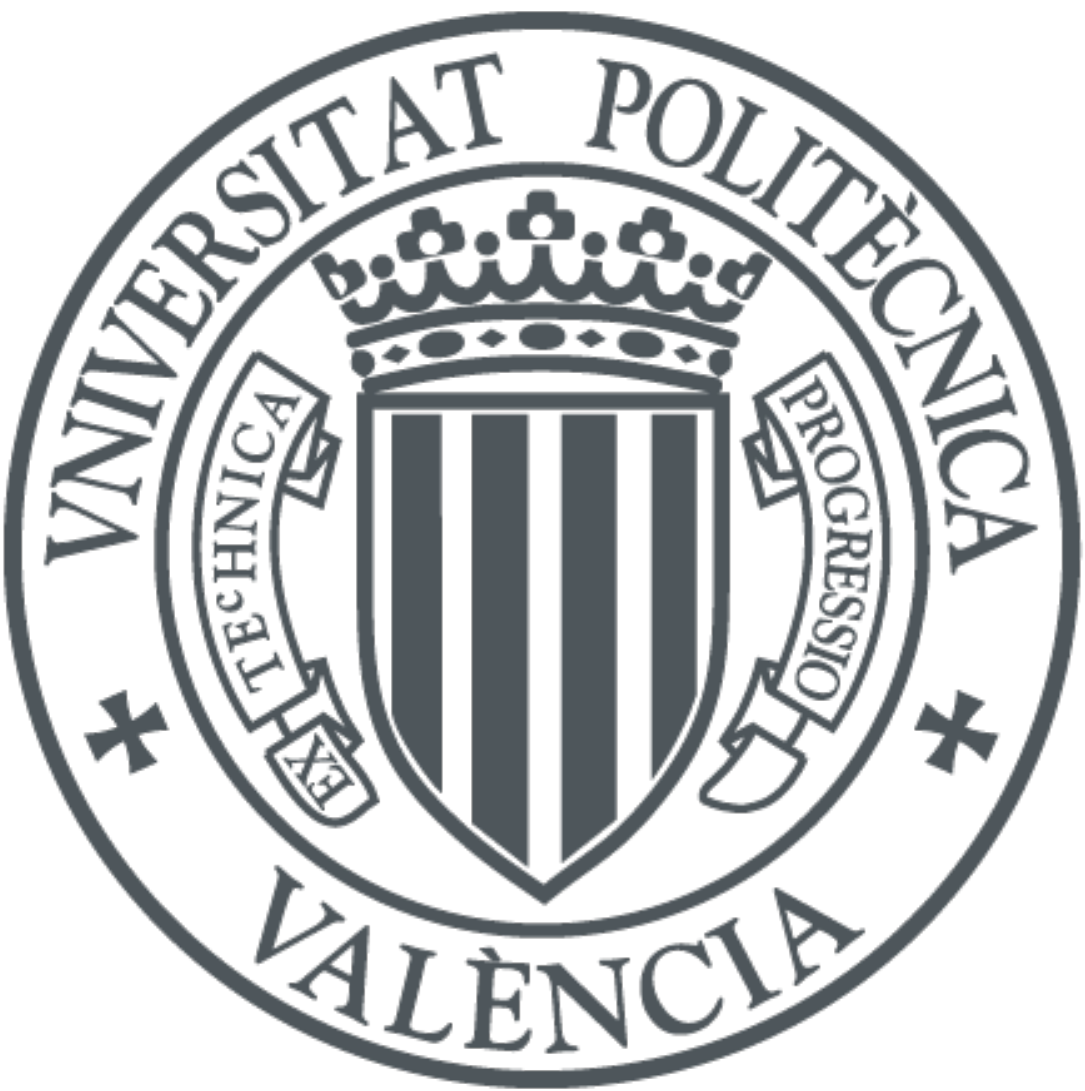

The final publication is available at

http://dx.doi.org/10.1080/14783363.2016.1216309

Copyright Taylor \& Francis (Routledge)

Additional Information 


\title{
DEVELOPING A PERFORMANCE MANAGEMENT MODEL FOR THE IMPLEMENTATION OF TQM PRACTICES IN PUBLIC EDUCATION CENTERS
}

\begin{abstract}
Achieving excellence in public education center management is a means to attain higher quality in education. This can be reached by implementing performance management. This article proposes a comprehensive management tool, in the form of a balanced scorecard (BSC), for non-university public education centers, using the EFQM excellence model as a framework for the implementation, evaluation and improvement of quality. This management system brings TQM practices to education centers and is specifically designed to cater for their individual requirements. In our study, a strategic map of these organizations was devised after cause and effect relationships were identified based on their strategic objectives, and after defining the different areas in which action was required. The Delphi method enabled us to obtain a set of indicators which were identified by experts as being particularly relevant for measuring performance and monitoring strategy. Based on a qualitative analysis of the results, a BSC was drawn up. Its validity and reliability were proved by the high level of consensus reached by the experts. This tool will lead to improved efficiency in the management of educational centers, and is a valuable instrument to better understand factors that determine the performance of educational management and the achievement of excellent results.
\end{abstract}

Key words: EFQM model; TQM; public education centers; balanced scorecard; Delphi method. 


\section{Introduction}

The international economic crisis has revealed a need for greater effectiveness in public administration in order to bring about more sustainable development. Loss of the public sector's credibility as a managing agent of citizens' wellbeing has led governmental institutions to act by applying principles of economy, efficiency and efficacy (Verbeeten \& Spekle, 2015). Public education centers have been included in the process undertaken to enhance managerial efficiency and effectiveness. New Public Management (NPM) has been included as a mechanism to improve the quality of education by increasing the managerial efficacy of schools and by applying principles from the business sector to the running of education centers (Campatelli, Citti \& Meneghin, 2011; Aoki, 2015). The essence of this philosophy lies in efficiency, efficacy and economy; that is, management that is capable of meeting customer (citizen) requirements at the lowest possible cost. Integrating these principles reflects the need to apply economy and efficiency criteria when using public resources, encouraging management tasks, and designing quality education projects.

To promote excellent management of educational institutions, Spain has selected the European EFQM (European Foundation for Quality Management) excellence model for education as the mainstay of its total quality management (TQM) (Calvo-Mora, Leal \& Roldán, 2005). Applying the TQM philosophy to an organization determines the need to monitor compliance with the established strategic objectives and, consequently, achieve management excellence, as well as the need to understand that such excellence involves the whole institution (Kanji, Malek \& Tambi, 1999). In this context, the fact that evaluation and quality are concepts linked by the same purpose has been further reinforced (Franceschini \& Turina, 2013). 
Introducing business management models in educational centres means having to adapt and standardize tools and techniques to the peculiarities of public education centers. Performance measurements need to be contextually specific, which means that composite indicators need to be tailored to each particular context (Schachter, 2010), and performance evaluation requires the selection of proper assessment evaluation tools. BSCs have proved to be the most efficient way to support management and strategic control (Lipe \& Salterio, 2000; Banker, Chang \& Pizzini, 2004), and the most popular tool employed by the organizations that apply TQM, out of the main systems used to measure performance (Julnes \& Holzer, 2001; Holzer \& Yang, 2004; Striteska \& Spickova, 2012). A BSC enhances the analysis of processes and promotes balance between objectives, indicators, targets and action plans. As a result, it is a comprehensive management model because it fulfills three basic tasks in an organization: it functions as a measuring system, as a strategic management system and as a communication tool. It complements the self-assessment task proposed by the EFQM model and has been extensively used in public-sector organizations (Chan, 2004; Wisniewski \& Olafsson, 2004; Pimentel \& Major, 2014). The literature on its use in the academic world mainly comprises case studies from universities (Franceschini \& Turina, 2013). Despite its application in the university education area, very little attention has been paid to using this tool in non-university public education centers.

In this article, we attempt to bridge this important gap and contribute to the literature in the following ways. Initially, we added quality management practices to the management of non-university educational centers as a means to improve the quality of education by increasing the managerial effectiveness of centers. Secondly, we provided a specifically designed tool, in the form of a BSC, to assess the performance management of a specific type of non-university public education centers, known as Public Vocational Training Centers 
(PVTC). Thirdly, we used a novel approach in terms of public organization literature by applying a qualitative methodology, i.e. the Delphi Method.

This paper is arranged as follows: Section 2 provides a description of PVTCs; Section 3 undertakes a brief review of the literature; Section 4 analyses the steps required to design a BSC; Section 5 introduces the research method and experimental design; Section 6 provides the results of applying the Delphi method, and assesses the quality of these results; Section 7 reflects the conclusions of our research and its contributions.

\section{Public Vocational Training Centers in the Spanish Education System}

Having a good quality education system is one of the key elements that defines a society's level of wellbeing and determines its future opportunities. Vocational training is today an especially important element of the Spanish education system from both a people perspective and a socio-economic viewpoint. From the human resource point of view, it enables young people to channel their vocations and provides them with skills to exercise a profession and acquire a suitable standard of living. It includes lifelong training programs for people in employment, which facilitate their promotion, as well as programs for unemployed workers that equip them with better skills to return to the labor market. From a socio-economic perspective, a good vocational training system allows companies to find qualified workers who facilitate the survival and progress of these companies in an increasingly competitive and global setting. Detecting the training needs of the production sector to guide the public training system in order to provide relevant qualifications is a starting point to design vocational training policies for employment.

Vocational training has acquired strategic value in Spain because of its capacity to meet the training demands of Spanish society as well as the requirements of the production sector. 
According to the Labor Force Survey (2015) carried out by the Spanish National Statistics Institute, in 2012 almost 4.4 million people had been trained under the above system. This represents approximately $20 \%$ of all the people eligible to work. The system provides training to people aged 16-65 years of age under two subsystems, which include activities that range from initial training, to exercising a profession and updating professional skills for people already in the labor market.

Public Vocational Training Centers (PVTCs) were created in Spain in their current form in 2005. They were conceived as places where learning was promoted for a large population with different interests, offering multidimensional learning resources. Adapting Spanish vocational training to a changing socio-economic context has meant having to make the system flexible in training terms, seeking improved efficiency and effectiveness to manage its resources. PVTCs were created during the economic crisis that Spain is still suffering, and public administration has had to integrate and constantly update business management practices to ensure it achieves higher levels of productivity, efficiency and effectiveness in its tasks. To this end, ever since these centers were set up, they have become a benchmark for integrating the two vocational training subsystems and their organizational and functional regulation, which addresses more efficient and efficacious management, and is defined in terms of excellence.

PVTCs have a pedagogical, organizational, economic and staff management model that guarantees their autonomy within today's legal framework. As such, each PVTC draws up a functional project to establish its organizational system, management procedures, the curricular projects for the vocational training on offer, teaching programs and a tutorial action plan. To guarantee the quality of actions in their center's functional project, these organizations have a continuous improvement system including quality criteria and indicators 
that are related to the objectives of this project in order to assess the numbers of job placements achieved by students, and their level of satisfaction.

\section{Literature review}

Concerns about improving student performance and setting up more efficient guidelines for educational center organization and management has driven the design of education management models everywhere (Sun \& Van Ryzin, 2014). The quality of education, in terms of education center management, is defined as including increasingly transparent results, promoting greater autonomy and specialization in these centers, and encouraging accountability from students, teachers and centers. These principles reflect the need to apply economy and efficiency criteria in using public resources to reinforce their autonomy, enhance management tasks, and design a quality education project that ensures the teaching center's specialization will guarantee quality teaching (Boyne and Chen, 2007).

The new Spanish legislation on education (LOMCE) maintains this trend of professionalizing management tasks in education centers, while introducing elements of business management. These elements become the strategic plan for the center's activity, developed through work programs and scheduled projects. This new conception of management is encouraged by increasing organizational autonomy and operations, and by acknowledging their input in improving the quality of teaching.

Quality management frameworks are becoming increasingly crucial in public administration due to the demands and expectations of stakeholders. They provide a structured approach to assessing service quality levels and organizational performance, and also help to identify where improvements can be made (Wisniewska \& Szczepanska, 2014). Evaluation and quality are concepts linked by the same purpose. This has had a reciprocal 
effect, and their outcome determines the strategic focal point for the education center to achieve the highest possible levels of efficiency and effectiveness in the management of its human and material resources.

The EFQM self-assessment model has been adopted in Spain for the education sector as the mainstay of the TQM philosophy. It has been conceived as a means to reach greater quality in education through excellent management of educational institutions. The literature on quality management reveals empirical studies containing successful approaches that support the reliability and validity of the European Excellence Model as a reference framework for the implementation, evaluation and improvement of quality (TQM) in the public sector (McFarlane, 2001; Oakland, Tanner \& Gadd, 2002; Madan, 2010; Wisniewska \& Szczepanska, 2014), and in higher education (Calvo-Mora, Leal \& Roldán, 2005; Mashhadi, Mohajeri \& Nayeri, 2008; Campatelli, Citti \& Meneghin, 2011; Tari \& Madeleine, 2011). In this context, Villa, Troncoso \& Díez (2015) analyzed the impact of quality management systems (implementation of EFQM) on the functioning of schools. Yet, there is still much debate as to whether the concept of "quality management" pertaining to the business field can be transferred to the sphere of education and if so, which special measures have to be taken (Arnold \& Kolbinger, 2013).

The most popular model used by organizations to identify performance measures and to support management and strategic control is the BSC. This tool is used to describe, implement and manage strategy at all organizational levels (Nayeri, Mashhadi \& Mohajeri, 2008), and it encourages the development of a better system to measure performance that is not only based on financial measures (Schwartz, 2005). The strategic objectives of an organization are translated into performance measures on the basis of four perspectives. Compared to other performance evaluations, the BSC focuses on both financial and non-financial aspects to 
assess and manage the executive condition of policies (Wu, Lin \& Chang, 2011). The BSC tool complements the self-assessment task proposed by the EFQM model, which stresses that any organization needs to include strategic planning in its work, and to ensure this work is being carried out. The BSC provides information that determines the efficiency and effectiveness of its implementation, and the effectiveness of the established objectives. It has been conceived to globally support strategy which, by complementing the work of the European Excellence Model, helps meet certain criteria indicated in it, enabling both to be viewed as excellent comprehensive management models (Trullenque, 2002).

The crux of the method lies in the design and implementation of the organization's vision and strategy in objective terms, and establishing a set of financial and non-financial performance indicators. The introduction to the BSC assumes that goals, indicators and strategic actions are all included in a specific viewpoint called perspective. The general BSC model is made up of four strategic perspectives: Financial, Customer, Internal Process, and Learning and Growth, which must be balanced. This proportionality is obtained by achieving impartiality between short- and long-term objectives; required inputs and outputs; internal and external performance factors, and financial and non-financial indicators (Striteska \& Spickova, 2012). The perspectives which offer a transparent view of the link between the organization's success and the controllers of its performance are those selected.

In international terms, BSCs have been extensively used in public-sector organizations (Chan, 2004; Wisniewski \& Olafsson, 2004; Mendes et al., 2012; Dreveton, 2013; Pimentel \& Major, 2014; Mensah \& George, 2015). This has led to several adaptations that intend to cater for certain peculiarities inherent to the public sector, which have implied introducing and amending its perspectives and reordering the cause and effect relationships that interconnect them. Both private- and public-sector organizations are tasked to produce value for 
stakeholders in their environments by deploying resources and capabilities, but they differ in the nature of the value, resources, capabilities and environments, and this has implications for strategy and its implementation (Alford, 2000). The public sector aims to serve society's needs and improve public welfare and while it is subject to budgetary constraints, it is also required to increase its standards of service efficiency and effectiveness (Johnsen, 2001). For some researchers, applying a BSC approach to the public sector means introducing certain conceptual changes to the original model, leaving its four perspectives as was, adapting its contents to the reality of public administration, and circumstantially altering the cause and effect relationships interconnecting these perspectives (Kaplan, 1999; Niven, 2003). Others, however, argue that any changes to be introduced must be of a structural type, and that it is absolutely necessary to eliminate, substitute, include and break down perspectives to better adapt the model to the reality of public management (Bastidas \& Ripoll, 2003; Niven, 2003; Barros \& Rodríguez, 2004).

The use of balanced scorecards in the academic world mainly focuses on studies into cases that have been applied in university institutions or departments (Kanji, Malek \& Tambi, 1999; Chen, Yang \& Shiau, 2006; Umashankar \& Dutta, 2007; Farid, Nejati \& Mirfakhredini, 2008; Beard, 2009; Chen, Wang \& Yang, 2009; Cugini, Michelon \& Pilonato, 2011; Wu, Lin \& Chang, 2011; Aljardali, Kaderi \& Levy-Tadjine, 2012; Franceschini \& Turina, 2013). An analysis of these papers shows that although there is no scientific evidence that the implementation of a BSC always leads to improved performance (Parajape, Rossiter \& Pantano, 2006), the approach is generally well suited to performance measurement system design in higher education. Although a list of performance indicators to be included in a performance measurement system is often proposed, a procedure for the analysis and redesign of a current set of indicators is not suggested (Franceschini \& Turina, 2013). 


\section{Designing a BSC for a Public Vocational Training Center}

The starting point in preparing a BSC is to identify the mission and vision of PVTCs (Kaplan \& Norton, 2004) which, as in all public organizations, will be determined by the corresponding legislation (Moreno \& Bastidas, 2011). From this strategic information perspective, the tasks that legal regulations attribute to such centers can be identified, as can the strategic objectives that can be assimilated to functions, given that these functions clearly define the management that governs centers (Cáceres \& González, 2005). The perspectives included in the BSC for PVTCs correspond to those originally created by Kaplan and Norton (1992), which they later adapted to non-profit organizations and to the public sector (Kaplan, 1999), together with what Niven contributed (2003) in terms of the restrictive function of the financial perspective and the cause and effect relationships deriving from this. The publicsector strategic map takes on a top-down cause and effect hierarchy consisting of customers, internal processes, learning and growth, and finance, which can be explained as follows: the financial perspective provides the necessary means for the growth of human capital, productivity, organizational capacity, and information in the learning and growth perspective, which, in turn, produces the work needed to succeed with the critical factors of the internal process perspective, and ultimately the customer perspective (Mendes et al., 2012). Given the social nature and public ownership of education, the 'Financial', 'Learning and Growth' and 'Internal Process' perspectives must be considered as drivers of the academic results obtained by users, and these results are the ultimate purpose of such organizations (Karathanos \& Karathanos, 2005).

Devising the strategic map involves establishing cause and effect relationships between all the established strategic objectives to test their validity as control elements (cause) and their impact on creating value for customers, and ultimately, to accomplish the organization's 
mission and vision (effect). Figure 1 shows the classification of strategic objectives, which clarifies the relationship between the various strategic objectives of BSC perspectives using a color code that reflects the 'chain' of the cause and effect relationship. It is worth highlighting the singularity represented by the color black used in the 'Customer' perspective. This does not express a cause and effect relationship with one or several strategic objectives, but with all of them. The effect that leads to all the strategic objectives being met from the other perspectives is reflected in the four key elements to be monitored, which are interrelated and respond to the common objective represented by creating value for customers, which is measured in terms of satisfaction. Mission and vision are seen at the top of the figure as the ultimate purpose of the strategy.

The sequence of the cause and effect relationships in the strategic objectives of each BSC perspective, which shapes the PVTCs' strategic map, lies behind the following philosophy:

a) The center's management should take a formal lead depending on the resources that it has available, and should promote and integrate a strategy-based culture as a requisite to enable its management to be efficient. This strategic culture will allow the center's staff to adopt this form of management much more easily, and will entail including them in a team to work in a coordinated manner, in which everyone knows their tasks and they all cooperate with other staff members to achieve greater efficiency and effectiveness when implementing the established strategy. The result will be the implicit need to promote and foster optimum staff training, and to create and facilitate suitable forms of communication to enable teamwork.

b) When the culture and staff are ready, the next step will be to determine the key internal processes to accomplish the outlined strategy. In addition to being "key factors of success", these processes must cover the main tasks that the organization performs. 
c) After determining these processes, which are essential for accomplishing both the mission and vision, it will be necessary to check the impact they have on customers in order to determine whether this strategy has generated "added value" that customers like, are satisfied with, and which they value positively.

Finally, it will be necessary to analyze whether apart from creating 'added value' for customers, the efficiency and effectiveness in using material and human resources has increased, and if it has helped to improve the results obtained while offering the main and ancillary services. Based on the above cause and effect philosophy, Figure 1 shows the classification of the strategic objectives in the various perspectives of the BSC and the relationships between them. These relationships are reflected by using a color code as the background format of the ellipses and circles that are interrelated and which may be white, gray or black, and directional connectors that reflect the cause and effect "chain". The uniqueness that black represents in the customer perspective stands out in this figure. This does not express a cause and effect relationship with one or more strategic objectives but rather with all of them. The effect that means all the strategic objectives of the other perspectives are attained is reflected in the four key factors to be monitored, which are interrelated and meet the common goal of creating value for customers, which in turn is measured in terms of satisfaction. Mission and vision are at the top of the figure as the ultimate goal to be achieved with the strategy followed via the relevant objectives.

After having identified the cause and effect relationships on the strategic map, relationships can be established between the different groups of strategic objectives. According to Figure 2, objective FO1 is the fundamental support from the financial viewpoint because, if fulfilled, the two objectives that complement it appear (FO2 and FO3) and are the starting point to meet existing objectives in the other perspectives. The fact that the 
'Customer' perspective has not been included in Figure 2 is of major interest. This is because Figure 2 reflects direct relationships between the objectives. As the global nature of the strategic objective that defines this perspective is not direct, its result depends on compliance with the previous ones, and also on the synergies formed between the objectives that define and interrelate them.

The next phase is to create indicators; that is, the measures that monitor and assess whether the strategic objectives are met. The indicators must be specifically defined for each strategic objective to be monitored, and consequently for each organization. For this reason, it is not feasible to employ a set of general reference indicators. The literature review enabled an initial proposal to be made of the most useful indicators in public education institutions (Karathanos \& Karathanos, 2005; Umashankar \& Dutta, 2007; Farid, Nejati \& Mirfakhredini, 2008; Wu, Lin \& Chang, 2011; Aljardali, Kaderi \& Levy-Tadjine, 2012; Franceshini \& Turina, 2013) (Figure 3). Yet despite comparing their usefulness, we were unable to order the most suitable indicators. Moreover, numerous indicators were generated, and this number had to be reduced to obtain a suitable number for the guidelines laid out by the theoretical frame (Kaplan \& Norton, 2004). In this situation, a lack of specific studies in this particular research field meant us having to resort to an exploratory research technique.

\section{Research setting and methodology}

When sources of data to be used for statistical analyses are not available, the most suitable resource to obtain information is by resorting to experts' opinions. This meant we drew on subjective information, for which we used the Delphi technique, based on qualitative principles, as we considered that this could provide us with the required results. This technique is a method of structuring communication between a group of experts who can 
supply useful information for the solution of a complex problem (Landeta et al., 2008). Its simplicity and flexibility make it adaptable to a wide range of different situations and requirements. Its primary aim is to obtain reliable opinions from a group of specialists or experts on the subject under study, so that the response of the group can be used to obtain a reasonable view of the future situation.

In forecasting research, Delphi-type qualitative methodologies can be a highly efficient resource for obtaining the information needed for a quantitative economic model. This information proceeds from the knowledge and experience that tacitly comes from judgments made by individual experts (an expert-based method). Delphi is a subjective intuitive and exploratory technique for foresight studies, based on the opinions of experts on the subject. Its underlying philosophy is the idea that the whole is greater than the sum of its parts (Eschenbach \& Geistauts, 1985). The superiority of a group judgment over individual judgment is thus recognized. The latter is found to be inefficient especially when complex problems must be solved in uncertain conditions with little available information (Sahal \& Yee, 1975). It is especially suitable for situations in which the best information available belongs to experts in the subject, since it is the technique best adapted to the exploration of elements that include a mixture of scientific evidence and social values (Webler et al., 1991). It possesses both quantitative and qualitative dimensions and has frequently been used in the context of political decisions, due to its capacity for providing an alignment of the expectations of the actors involved by means of iterations (Blind, 2008).

It stands out for its flexible design, not requiring any physical contact among experts (Hayes, 2007). In addition, expert panel size requirements are relatively modest (Okoli \& Pawlowski, 2004). Despite the progress that this technique has made, its key design elements are still anonymity, iteration, controlled feedback and participating experts (Landeta, Barrutia 
\& Lertxundi, 2011; Nowack, Endrikat \& Guenther, 2011; Rowe \& Wright, 2011). Anonymity is achieved by using questionnaires, and their successive iteration in different rounds allows individuals to re-consider or even modify their views without needing to meet the rest of the group. Controlled feedback is provided between iterations, so that the members are aware of the anonymous opinions of their colleagues. The group response is arrived at by calculating the statistical mean of individual estimations in the final round.

Currently, the Delphi method is a popular prospecting technique that has been frequently used for a wide range of problems in very different fields of knowledge, including, among others, business, education, health care, real estate, engineering, environment, social science, tourism, transportation and information systems. Its most popular areas of use are the economy, finance and business, medicine and nursing, psychology and education. It has also been successfully employed in quantitative approaches (Landeta, 2006; Landeta et al., 2008; Mateos-Ronco \& Server, 2011; Wu, Lin \& Chang, 2011; Delbari et al., 2016; Lin et al., 2016). Although its use is widespread, the Delphi method suffers from certain limitations, which means that the results have to be interpreted with caution on occasions (Gupta \& Clarke, 1996). It is often criticized for its questionable statistics and sampling methods (Sackman, 1974) and some authors cast doubt on its utility and classify it as an exploratory research tool (Steinert, 2009). However, its knowledge-generating capacity and ability to offer effective and efficient expert-based foresight into a subject is in no doubt. In fact, the results of comparative studies with traditional group techniques (statistical groups, direct interaction groups) have shown Delphi to be superior (Landeta, 2006).

Given that the present study requires human judgment on different economic and social aspects, we considered the Delphi method was the best tool available, due to its ability to provide information on a situation for which a statistical model was ruled out on the grounds 
of a lack of historical data. Perhaps the strongest argument in its favor in our case was the need to consider divergent opinions and reach consensus on different views of PVTC management. Different authors (Turoff, 1970; Rowe, Wright \& Bolger, 1991; Woudenberg, 1991) point out that the Delphi method not only seeks to reach consensus, but more importantly identifies diverse opinions. This interpretation has given rise to a variation of the traditional method, which has been used in different studies (Tapio, 2002; Steinert, 2009) designed to deal with these divergent opinions. To these advantages, we can add another reason to use the Delphi method. An essential BSC concept is the establishment of hypothesized cause and effect linkages between performance measurements and strategic objectives. Since a scorecard-linked compensation system's effectiveness relies heavily on targets and weights, a consensus about casual linkages is important for implementing a truly successful BSC system (Herath, Bremser \& Brinberg, 2010). Delphi can identify divergent opinions and harmonize attitudes about the most suitable indicators.

The initial hypothesis we put forward when choosing the methodology was that a group of recognized experts in the management of the educational centers under study would together accumulate more experience and knowledge than the sum of the individual members. The combined judgment of the group, which had a highly developed capacity for criticism, was considered to be more suitable than any one individual to identify the most suitable design for the BSC. In order to apply this method, we selected a group of experts who undertook strategic-type work in the organizations under study. Furthermore, their experience and knowledge in both the teaching and management of these centers enabled a valid critical analysis in order to prepare a methodological BSC proposal for PVTCs. Each expert had to indicate the suitability of the proposed indicators (Figure 3) and place them in order, 
according to how well they measured each strategic objective for each perspective, in an attempt to agree on differences in their opinions through this method.

\subsection{Group of experts}

Since the selection of performance indicators was processed by professional questionnaires, we chose experts who possessed professional knowledge of center management and organization and were well-experienced to be our panel. We selected a group of experts who worked in the organizations under study. The following selection criteria were adopted:

$\checkmark$ Professional experience. Occupying job positions related to strategic planning in the centers under study was a key aspect in understanding their strategic objectives, and in linking them to the proposed follow-up and control indicators so as to differentiate and select those that fulfilled tasks effectively and efficiently, and also by considering criteria of utility, simplicity and agility to collect the information that fed them.

$\checkmark$ Technical training. The fact that the process involved dealing with technical-scientific elements meant that experts had to know and master different aspects related to strategic planning and control. Training in these matters also had to be a determinant because the assessment of various matters under study required having previous training in them to know and apply concepts methodologically.

Accordingly, and based on these criteria, it was deemed that the people involved in management work would be the most suitable members of the group of experts, given the operations and organization of these institutions. The management teams of these centers are made up of a principal, vice-principal, head of studies, secretary and vice-secretary. Experience acquired from performing their tasks, and the technical training stemming from 
their strategic work in the various management areas, meant that their inclusion in the panel of experts was both significant and necessary. In addition to these managers, the position of quality coordinator was also included in this group, given the technical profile of these professionals in quality management issues and the counseling work they do in these centers.

The backgrounds of the experts solicited for opinions were divided into two groups: (1) Experts in staff management and academic service, which included participants with roles in staff administration at the center and in providing educational services; and (2) Experts on financial, administrative and ancillary service management who had a more technical profile and whose roles supported the core activities of the education center. The first group consisted of 11 experts including principals, vice-principals and heads of studies at the centers. The second group was made up of nine experts who were secretaries, vice-secretaries and quality coordinators. Between them, the two groups delivered across-the-board representation of the population of the centers under study, which were all governed by the same substantive regulations.

\subsection{Questionnaire}

The questionnaire (Appendix A) was structured as follows and featured:

1. General information about the work that the experts carried out in the center, and how they characterized the center's activity profile. It included informative questions with objective responses.

2. Assessment of the indicators. This section was arranged according to two elements: strategic objectives and control indicators. Strategic objectives were grouped according to the BSC perspectives and the interrelation defined in the strategic map. The experts had to comprehensively read the objective and place the indicators in order, where the 
indicator considered fundamental came first, and the indicator that was accessory came last.

\subsection{Carrying out the process}

Consultations with experts were made in two rounds. The questionnaire was sent by email. In the first round, which took place between June and July 2014, of the 62 experts invited, 20 participated. The responses obtained in this first round were analyzed, and we obtained the degree of agreement shown by the experts in terms of the order of the indicators. Then, this first group response was sent again separately to the experts in an individual document. This document showed each initial individual response to the questions, along with the group answers, to help the experts decide whether to maintain the response they had chosen in the first round or amend it, according to the group answers. At the same time, the questionnaire first sent to the experts was adapted by eliminating the questions for which an agreement had been reached. The second round was carried out between October and November 2014. On this occasion, the same 20 experts involved in the first round also participated.

\section{Results and discussion}

The degree of consensus reached by the experts was identified by weighting the responses and correcting biases. Experts were not selected at random, but were chosen according to their high degree of training and work specialization. When applying the Delphi method to this selection of experts, a consensus was assumed when one item with two alternatives accumulated $70 \%$ of the responses, or when one question item with multiple responses accumulated at least $50 \%$ of the responses (Rowe \& Wright, 1999; Landeta et al., 2008). As a 
control measure, the median was calculated as a centralization parameter because it characterized the group's central response and eliminated the influence of aberrant phenomena, which affect the calculation of means. This calculation acted as a complementary instrument for selecting the group response when the frequency percentages established by the consensus were not reached. In these cases, the median provided information about the general response trend, and its value was taken as a reference to determine the consensus.

\subsection{Results of the first and second round}

Table 1 shows the final results of the frequencies and median analyses based on the experts' responses. In this table, the order conferred by experts to each indicator is shown in bold when considering the position that presents the highest degree of consensus (the 'Response Frequency' column). Likewise, if this consensus value equals or is over $50 \%$, its position in the order is also shown in bold in the 'Hierarchical Order' column in relation to all the other indicators. A value of ' 1 ' indicates that the indicator in question was the first one chosen to measure the corresponding strategic objective, and a value of ' 2 ' was the second one chosen, and so on.

The objectives FO3, LDO3, LDO4, IPO1, IPO4 and IPO5 led to consensus in all the indicators after the first round. Therefore, they were not included in the second round. The information collected after the second and final round was analyzed by the same parameters used in the first round. In this case, the median was observed if a response frequency of $50 \%$ was not reached; if this indicated a position that agreed with the highest percentage of response frequency, this position was selected as the consensus position, and this circumstance was indicated in bold. After this final round, consensus was reached for the 
strategic objectives LDO2, LDO5, IPO2, IPO3 and CPC, which left seven objectives that did not show sufficient agreement over the hierarchical order of the indicators.

\subsection{Validating the results}

The result of a Delphi analysis is more than a statistical combination of individual expert responses and requires a final evaluation of the reliability and validity of the evidence obtained. For this purpose, the results were analyzed for three different control situations: dispersion/consensus of the responses; stability of the experts' opinions; and expert participation.

\subsubsection{Dispersion/consensus}

To measure the degree of dispersion, the standard deviation (SD) of the various resulting distributions was selected. The small number of estimations per item, and the differences in size between the mean values of each item, meant that this statistic was selected as opposed to the interquartile range or coefficient of determination (Landeta et al., 2008). This circumstance implied calculating the individual SD of each indicator for all the strategic objectives in each of the two rounds. The overall results of all the perspectives, as a whole, are provided in Table 2. Here the data indicate the arithmetic mean of those calculated for each strategic objective.

A general positive trend in the degree of consensus was observed, which derived from the lower degree of dispersion of the response distributions in the second round as opposed to the first. The degree of dispersion only worsened for seven indicators. There was only one case, CAS_CTA, which had zero variation, and this indicator was included in both the first and second rounds. This allowed us to understand that having general information on responses made by the other panelists enabled them all not only to reflect on the judgments of a value 
given in the first round, but to also amend responses they might have been unsure about. From the second round, convergence was no longer significant as all the experts knew the opinion of all the other participating experts, so it was less likely that they would have modified their responses in statistical terms (Landeta et al., 2008). This conclusion implies that two rounds is the limit for this research because after this figure, further rounds would not have provided any more significant information.

\subsubsection{Stability}

In order to measure the stability of the responses, three complementary forms were employed: qualitative group stability, by calculating the percentage of indicators in which each expert maintained their first round opinion in the second round; quantitative group stability, which reflects the degree of variation rather than the number of variations, and absolute individual stability, or the number and percentage of experts who did not amend any estimations in the second round. The results per strategic objective and per perspective are provided in Table 3.

The data reveals that between $40 \%$ and $60 \%$ of the participating experts varied their hierarchical order of indicators in the second (qualitative stability) round. The 'Users' case in the 'Customer' perspective stands out, presenting broader variation, as there was a larger number of indicators to prioritize, which meant an increasing likelihood of modifications. When quantifying the variations in the experts' responses (quantitative stability), it should be noted that the hierarchical order of the indicators varied in $66 \%$ of the strategic objectives. In the remaining $34 \%$, greater stability was observed in the order of the indicators per objective, although the percentage of changes of opinion was high (75-80\%) in the position occupied by some indicators in the group per objective. Finally, including the absolute stability values of experts' responses in relation to each strategic objective revealed that the number of 
participants that had varied their responses between the first and second round when completing the questionnaire was over $45 \%$ in all cases.

From the global results, we can see that when we grouped the strategic objectives per perspective, the stability values converged: around $43 \%$ when measuring the experts who maintained the responses provided in both rounds (qualitative stability), and about $93 \%$ for the magnitude of the changes made by the experts in the order they prioritized the indicators in both rounds (quantitative stability). In line with the analysis per strategic objective, absolute individual stability confirmed the previous parameters, which helped validate the trend shown in all of them.

Regardless of whether the analysis of the previous results was performed in an aggregate manner, by blocks of strategic objectives or as perspectives, it still confirmed the stability requirement in the experts' consultation as an element of quality, coherence and validity for the obtained results.

\subsubsection{Participation and representativeness}

The last section of the results relates to the participation and representativeness of the group of experts. The most representative group members in both rounds corresponded to experts who occupied the positions of secretary and vice-secretary $(35 \%)$ in their centers, followed by the head of studies (30\%), while fewer quality coordinators participated $(10 \%)$. After the first round, participation was $33 \%$ of the total study population who were asked to complete the questionnaire, i.e. 20 participants. This number of experts was acceptable according to the method's requirements, especially if we bear in mind that the suggested margin for good method usage is 7-50 people (Okoli \& Pawlowski, 2004). It is also noteworthy that no panelist voluntarily dropped out of the process in either of the rounds. 


\subsection{The Balanced Scorecard of PVTCS}

Statistically validating the results enabled us to draw up a list of indicators which, according to the experts, should be included in a BSC for the organizations under study. These indicators were hierarchically ordered per strategic objective, and were assigned to a control perspective (Appendix B). The results reflect a proposal comprising 58 indicators. This number is too large because it would involve a great deal of effort to collect information, record it all, analyze it and then make decisions. The number and usual distribution of indicators for BSC perspectives tends to be: a) Financial: five indicators $(22 \%)$; b) Learning and Growth: five indicators $(22 \%)$; c) Internal Process: from eight to ten indicators $(34 \%)$, and d) Customer: five indicators (22\%) (Kaplan \& Norton, 2004).

Karathanos and Karathanos (2005) indicated that for education institutions, the number of indicators must be between 20 and 40. Umashankar and Dutta (2007) pointed out that successfully applying a comprehensive control panel lies in using 15-20 indicators to control the organization strategy. Other authors, like Escobar (2007), did not recommend using more than two indicators per strategic objective to perform a clear follow-up of a strategic objective by indicators. Aljardali, Kaderi \& Levy-Tadjine (2012) reinforced this statement and established that indicators must be linked to strategic objectives, stating that no more than two should be used to control them because a larger number would mean having to break down this objective into two. The aforementioned variants and contributions respond to efficiency and effectiveness criteria when applying a BSC to a variety of organization types. Determining the final number of indicators and their proportion per perspective in the BSC of the education centers under study responded to selections based on the hierarchical order obtained after applying the Delphi method. The proposed indicators, assessed by the panel of experts, represented several alternatives to measuring compliance with a given strategic 
objective. Following the experts' prioritization process and the conclusions compared in the bibliography, a combination of both criteria was used to determine the number and final proportion of the BSC model indicators for PVTCs. The model used to select indicators took into account the criteria set out below, the establishment of which implied greater scientific rigor: (1) the number of indicators per perspective was determined as a percentage, according to the number of strategic objectives to be measured, which was set at one per strategic objective; (2) if the response frequency among the indicators resulted in a "draw", which gave no consensus in the experts' opinions, the one with the lowest degree of dispersion in the response was used. The degree of stability shown from one round to the next was also considered; (3) when no consensus was reached about the indicator that came first in the hierarchical order in terms of an objective, the indicator which came second in this order (hierarchical position 2) was used. Consequently, in all the cases in which a key indicator was not determined to measure the corresponding strategic objective in accordance with general statistical models (response frequency, median) for experts' responses, criteria from previous works were used. Table 4 shows the final BSC obtained for the PVTC. Appendix C shows the method of calculating each of the quantitative indicators proposed in each perspective. The sources for obtaining data were extremely varied, consisting of reports, records, lists and other documentary references specific to the administration of the centers. The qualitative indicators, which were all within the 'Customer' perspective and were calculated by determining the level of user satisfaction, were obtained from interviews and surveys of stakeholders (users, staff, production sector, education administration and society).

\section{Conclusions}


This work is a valuable contribution to the implementation of performance management in non-university public teaching centers and covers the current gap in specific tools for these public organizations. The hypothesis of this research, which assesses the use of a BSC for the comprehensive management of PVTCs, has been corroborated by the results obtained. This performance measurement system is based on the EFQM self-assessment model and TQM principles and offers the organization an opportunity to learn about its own strengths as well as critical areas for improvement, orienting their management efforts towards the achievement of excellent results. However, the ability of a BSC to adapt to a public sector management philosophy does not make it an instrument that unequivocally guarantees the organization's success. To prevent this management tool from not living up to expectations and despite methodological limitations, the Delphi method enabled the designed BSC to completely adapt to the characteristics and determining factors of the centers where it will be used. This fact facilitates standardized adoption in these organizations.

Adequate sequencing of cause and effect relationships is a key factor for a successful BSC. Analyzing causal relationships among cause and effect factors is a reference for improvement for decision-makers. The validity of the indicators selected, prioritized and tested using the subjective information from experts stemmed from the high degree of consensus reached by experts in hierarchizing indicators for each strategic objective. A consensus was reached for 47 of the 58 indicators $(81 \%)$. It is worth noting that no total consensus was reached in relation to the order of the indicators for nine $(47 \%)$ of the 19 strategic objectives, and only four were not determined as a main indicator to measure the corresponding objective $(21 \%)$. Thus, lack of consensus refers only to the indicators that occupied the second and furthest positions. In the perspective analysis, it should be pointed out that the 'Learning and Growth' and 'Internal Process' perspectives presented unanimity as 
the most suitable indicators to control strategic objectives. This could be due to the fact that in the practical functioning of centers, internal procedures are the core value of an organization's operations, and experts have tacitly assessed this. If this could be improved and adjusted continually, an organization's entire performance might be able to benefit from constant upgrading (Wu, Lin \& Chan, 2011). However, discrepancies were found in three of the five objectives proposed for the 'Customer' perspective. The 'Financial' perspective showed a low level of agreement, which was reached for only one of the three objectives when the key indicator was selected. This could be attributed to the fact that the financial perspective is viewed as a budgetary restriction for the center's management team when it comes to providing resources for the development of education programs. In the public sector, the financial perspective is not the goal but an impediment that must be optimized. The amount of financial resources that a center's managers have is not a variable they can currently control. Accordingly, any agreement on this point is more difficult as managers' judgments may be influenced by their own expectations.

The coincidence of the strategic objective with other public organizations stands out in the 'Financial' perspective. This objective aims for efficiency, and is measured by strategic budget distribution, the control of variations while being carried out, and the expense per user of the services these centers offer. The 'Learning and Growth' perspective reinforces the relevance of aspects related to new technologies and the center's staff. The control of new technologies applied to teaching and management, along with the reinforcement of teacher/administration staff training and services, are seen as key elements to measure. This also affects other perspectives, such as 'Internal Process' and 'Customer'. Therefore, centers should encourage their staff to enhance their learning and growth. In this context, the BSC enables staff to construct an explicit target of work as well as further raising satisfaction, so 
that employees will focus on contributing more to advance the other three perspectives. The relationship with production, the evaluation of academic training and excellent management are the most widely used indicators to ascertain the extent of meeting the objectives that group the 'Internal Process' perspective. These indicators synthesize the essential aspects to which an educational organization must apply quality criteria as their result is that perceived by groups of interest. Former users' satisfaction with the academic training received, the education center's cooperation with social and economic agents, and the functioning of the organization vis-à-vis human resources and the education administration were the indicators selected to be measured in the 'Customer' perspective.

From a political and social viewpoint, the results support the reliability and validity of the EFQM as a reference framework for the implementation, evaluation and improvement of quality practices in the area of public vocational training, and this has practical implications for management. TQM implementation will positively affect the overall quality of educational services. Therefore, the EFQM model can be successfully used by this type of public education centers. Assessment of the impact of quality management systems in non-university education centers should focus on the three aspects that explain the center's activity and the effects on its operations: the teaching and learning process, center management and relationships with its surroundings (Villa, Troncoso \& Díez, 2015). The inclusion of a BSC as a comprehensive management methodology for strategy would help as a working guide for the latter two aspects, and could help policy makers to better understand factors that determine educational performance management. Obtaining the advantages, disadvantages, opportunities and threats of centers from both internal and external organizational viewpoints, including the customer, internal process, learning and growth of staff, and financial perspectives, could further develop strategies and schemes to improve, thus enhancing the 
entire operating performance of these centers. The BSC should be used as a guide for implementing and conveying strategy and as a system for understanding what really creates value for education centers and not just as a mere performance measurement system.

Without prejudice to the conclusions derived from the results obtained and considering their high degree of validity and reliability, our research has its limitations. First, applying the Delphi method in a personalized manner was not suitable for finance, thus this was applied by using ICTs. Although employing this method is useful and inexpensive, it entails losing potential participants who, if treated personally, would have contributed their knowledge to the study which, in turn, would have enriched the results. Secondly, the conceptual analysis of the centers that this study targeted was carried out in Spain given the relationship between these centers' objectives and the regulations that govern them. However, the lessons learned from an individual context will be shown to be equally applicable in the wider public education sector context, as the methodology and the obtained results are perfectly valid for other similar organizations in comparable contexts. Future research should continue to apply the BSC to educational centers to define target values, and to monitor and evaluate the model over time.

\section{References}

Alford, J. (2000). The implications of "Publicness" for strategic management theory. Exploring public sector strategy. Financial Times Prentice Hall, Harlow, pp. 1-16.

Aljardali, H., Kaderi, M. \& Levy-Tadjine, T. (2012). The implementation of the balanced scorecard in Lebanese public higher education institutions. Procedia - Social and Behavioral Sciences 62, 98-108. 
Aoki, N. (2015). Institutionalization of New Public Management: the case of Singapore's education system. Public Management Review 17, 165-186.

Arnold, P. \& Kolbinger, M.L. (2013). Establishing quality assurance for e-learning in higher education: challenges, initial concepts and process reflection. 7th International Technology, Education and Development Conference, INTED Proceedings, 4823-4832.

Banker, R.D., Chang, H.S. \& Pizzini, M.J. (2004). The balanced scorecard: Judgmental effects of performance measures linked to strategy. Accounting Review 79, 1-23.

Barros, J. \& Rodríguez, R. (2004). Una nueva visión del cuadro de mando integral para el sector público. Revista Iberoamericana de Contabilidad de Gestión, 2 (4), 117-148.

Bastidas, E. L. y Ripoll, V. (2003). Una aproximación a las implicaciones del Cuadro de Mando Integral en las organizaciones del sector público. Revista Compedium, 6, (11), 23-41.

Beard, D.F. (2009). Successful Applications of the Balanced Scorecard in Higher Education. Journal of Education for Business 84, 275-282.

Blind, K. (2008). Regulatory foresight: Methodologies and selected applications. Technological Forecasting and Social Change, 75, 496-516.

Boyne, G.A. and Chen, A.A. 2007. Performance targets and public service improvement. Journal of Public Administration Research and Theory 17 (3), 455-477.

Cáceres, J. y González, M. J. (2005). Hacia una gestión estratégica de los departamentos universitarios: propuesta de un cuadro de mando integral. Auditoría Pública 35, 55-72.

Calvo-Mora, A.; Leal, A. \& Roldán, J.L. (2005). Relationships between the EFQM model criteria: a study in Spanish universities. Total Quality Management \& Business Excellence 16 (6), 741-770. 
Campatelli, G.; Citti, P. \& Meneghin, A. (2011). Development of a simplified approach based on the EFQM model and Six Sigma for the implementation of TQM principles in a university administration. Total Quality Management \& Business Excellence 22 (7), 691-704.

Chan, Y. (2004). Performance Measurement and Adoption of the Balanced Scorecards: A Survey of Municipal Governments in the USA and Canada. The International Journal of Public Sector Management 2/3, 201-222.

Chen, S. H.; Yang, C. C. \& Shiau, J. Y. (2006). The application of balanced scorecard in the performance evaluation of higher education. The TQM Magazine 18, 190-205.

Chen, S.H., Wang, H.H. \& Yang, K.J. (2009). Establishment and application of performance measure indicators for universities. The TQM Magazine 3, 220-235.

Cugini, A.; Michelon, G. \& Pilonato, S. (2011). Performance measurement in academic departments: the strategy map approach. Public Money \& Management 31 (4), 271-278.

Delbari, S.A., Ng, S.I., Aziz, Y.A. \& Ho, J.A. (2016). An investigation of key competitiveness indicators and drivers of full-service airlines using Delphi and AHP techniques. Journal of Air Transport Management 52, 23-34.

Dreveton, B. (2013). The advantages of the balanced scorecard in the public sector: beyond performance measurement. Public Money \& Management 33 (2), 131-136.

Eschenbach, T. \& Geistauts, G. (1985). A Delphi Forecast for Alaska. Interfaces 15, 100-109. Escobar, T. (2002). El cuadro de mando integral como herramienta para el control de gestión: el estudio de un caso. Revista Española de Financiación y Contabilidad 33 (123), 1065-1102. 
Farid, D.; Nejati, M. \& Mirfakhredini, H. (2008). Balanced Scorecard application in universities and higher education institutes: Implementation guide in an Iranian context. Annals of University of Bucharest, Economic and Administrative Series 2, 31-45.

Franceschini, F. \& Turina, E. (2013). Quality improvement and redesign of performance measurement systems: an application to the academic field. Quality \& Quantity 47, 465-483.

Gupta, U.G. \& Clarke, R.E. (1996). Theory and applications of the Delphi technique: a bibliography (1975-1994). Technological Forecasting and Social Change 53, 185-211.

Hayes, T. (2007). Delphi study of the future of marketing of higher education. Journal of Business Research 60, 927-931.

Herath, H.S.B.; Bremser, W.G. \& Brinberg, J.G. (2010). Joint selection of balanced scorecard targets and weights in a collaborative setting. Journal Accounting and Public Policy 29, 4559.

Holzer, M. \& Yang, K.F. (2004). Performance measurement and improvement: an assessment of the state of the art. International Review of Administrative Sciences 70, 15-31.

Johnsen, A. (2001). Balanced scorecard: theoretical perspectives and public management implications. Managerial Auditing Journal 16 (6), 319-330.

Julnes, P.D. \& Holzer, M. (2001). Promoting the utilization of performance measures in public organizations: An empirical study of factors affecting adoption and implementation. Public Administration Review 61, 693-708.

Kanji, G.K. Malek, A. \& Tambi, B.A. (1999). Total quality management in UK higher education institutions. Total Quality Management 10 (1), 129-153. 
Kaplan, R. \& Norton, D. (1992). The balanced scorecard: measure that drive performance. Harvard Business Review 70 (1), 71-9.

Kaplan, R. (1999). The Balanced Scorecard for Public-Sector Organizations. Balanced Scorecard Report. Boston: Harvard Business School Publishing.

Kaplan, R. \& Norton, D. (2004). Strategy maps: converting intangible assets into tangible outcomes. Boston: Harvard Business School.

Karathanos, D. \& Karathanos, P. (2005). Applying the balanced scorecard to education. Journal of Education for Business 80, 222.

Landeta, J. (2006). Current validity of the Delphi method in social sciences. Technological Forecasting and Social Change 73 (5), 467-482.

Landeta, J., Matey, J., Ruíz, V. \& Galter, J. (2008). Results of a Delphi survey in drawing up the input - output tables for Catalonia. Technological Forecasting and Social Change 75, 3256.

Landeta, J., Barrutia, J. \& Lertxundi, A. (2011). Hybrid Delphi: a methodology to facilitate contribution from experts in professional contexts. Technological Forecasting and Social Change 78, 1629-1641.

Lin, M.H., Hu, J.Y., Tseng, M.L., Chiu, A.S.F. \& Lin, C.Y. (2016). Sustainable development in technological and vocational higher education: balanced scorecard measures with uncertainty. Journal of Cleaner Production 120, 1-12.

Lipe, M.G. \& Salterio, S.E. (2000). The balanced scorecard: Judgmental effects of common and unique performance measure. Accounting Review 75, 283-298. 
Madan, P. (2010). An award journey for business excellence: the case study of a public sector unit. Total Quality Management \& Business Excellence 21 (12), 1343-1364.

Mashhadi, M.M., Mohajeri, K. \& Nayeri, M.D. (2008). A quality-oriented approach toward strategic positioning in higher education institutions. Proceedings of World Academy of Science, Engineering and Technology, Vol. 27, 338-342.

Mateos-Ronco, A. \& Server, R. J. (2011). Drawing up the official adjustment rules for damage assessment in agricultural insurance: Results of a Delphi survey for fruit crops in Spain. Technological Forecasting and Social Change 78, 1542-1556.

McFarlane, D.G. (2001). Managing improvement in the public sector. Total Quality Management 12 (7-8), 1047-1053.

Mendes, P., Santos, A.C., Perna, F. \& Ribau, M. (2012). The balanced scorecard as an integrated model applied to the Portuguese public service: a case study in the waste sector. Journal of Cleaner Production 24, 20-29.

Mensah, W. \& George, B.P. (2015). Performance management in the public sector: ac actionresearch based case study in Ghana. Journal of Applied Economics and Business Research 5 (2), 97-111.

Moreno, Z. \& Bastidas, E. L. (2011). Un modelo multidimensional basado en el cuadro de mando integral, para la gestión de políticas educativas en el sector universitario. Revista Copérnico VII (13), 5-11.

Nayeri, M.D., Mashhadi, M.M. \& Mohajeri, K. (2008). Universities strategic evaluation using Balanced Scorecard. Proceedings of World Academy of Science Engineering and Technology, Vol. 27, 332-337. 
Niven, P. R. (2003). Balanced Scorecard Step-by-Step for Government and Nonprofit agencies. Mississauga: John Wiley and Sons, Inc.

Nowack, M., Endrikat, J. \& Guenther, E. (2011). Review of Delphi-based scenario studies: Quality and design considerations. Technological Forecasting and Social Change 78, 16031615.

Oakland, J., Tanner, S. \& Gadd, K. (202). Best practice in business excellence. Total Quality Management 13 (8), 1125-1139.

Okoli, C. \& Pawlowski, S. D. (2004). The Delphi method as a research tool: an example, design considerations and applications. Information and Management 42, 15-29.

Paranjape, B., Rossiter, M. \& Pantano, V. (2006). Insights from the Balanced Scorecard. Performance measurement systems: successes, failures and future - a review. Measuring Business Excellence 10 (3), 4-14.

Pimentel, L. \& Major, M.J. (2014). Quality management and a balanced scorecard as supporting frameworks for a new management model and organizational change. Total Quality Management \& Business Excellence 25 (7-8), 763-775.

Rowe, G., Wright, G. \& Bolger, F. (1991). A reevaluation of research and theory, Technological Forecasting and Social Change 39, 235-251.

Rowe, G. \& Wright, G. (1999). The Delphi technique as a forecasting tool: issues and analysis. International Journal of Forecasting 15, 353-375.

Rowe, G. \& Wright, G. (2011). The Delphi technique: Past, present, and future prospects. Introduction to the special issue. Technological Forecasting and Social Change 78, 14871490. 
Sackman, H. (1974). Delphi assessment: expert opinion, forecasting and group process. The Rand Corp. R-1283-PR, Santa Monica.

Sahal, D. \& Yee, K. (1975). Delphi: an investigation from a Bayesian viewpoint. Technological Forecasting and Social Change 7(2), 165-178.

Schachter, H.L. (2010). Objective and subjective performance measures: a note on terminology. Administration \& Society 42, 550-567.

Schwartz, J. (2005). The Balanced Scorecard Versus Total Quality Management: Which is Better for Your Organization?. Military Medicine 170, 855-858.

Spanish National Statistics Institute (2015). Statistical Yearbook of Spain 2015. Madrid: National Institute of Statistics.

M. Steinert, M. (2009). A dissensus based online Delphi approach: an explorative research tool. Technological Forecasting and Social Change 76, 291-300.

Striteska, M. \& Spickova, M. (2012). Review and comparison of performance measurement systems. Journal of Organizational Management Studies 2012, 13.

Sun, S. \& Van Ryzin, G.G. (2014). Are Performance Management Practices Associated With Better Outcomes? Empirical Evidence From New York Public Schools. American Review of Public Administration 44, 324-338.

Tapio, P. (2002). Disaggregative Policy Delphi: using cluster analysis as a tool for systematic scenario formation, Technological Forecasting and Social Change 70, 83-101.

Tari, J.J. \& Madeleine, C. (2011). Preparing Jordanian university services to implement a quality self-assessment methodology. International Review of Administrative Sciences 77 (1), $138-158$. 
Trullenque, F. (2002). Cómo Alienar Estratégicamente el Presupuesto: Balanced Scorecard y Presupuesto Estratégico. Estrategia Financiera 182, 20-26.

Turoff, M. (1970). The design of a policy Delphi. Technological Forecasting and Social Change 2(2), 149-171.

Umashankar, V. \& Dutta, K. (2007). Balanced scorecards in managing higher education institutions: an Indian perspective. International Journal of Educational Management 21, 54 $-67$.

Verbeeten, F.H.M. \& Spekle, R.F. (2015). Management Control, Results-Oriented Culture and Public Sector Performance: Empirical Evidence on New Public Management. Organization Studies 36 (7), 953-978.

Villa Sánchez, A., Troncoso Ruiz, P.E. \& Díez Ruiz, F. (2015). Latent structure and reliability of dimensions that explain the impact of quality management systems on schools. Revista de Investigación Educativa 33 (1), 65-82.

Webler, T., Levine, D., Rabel, H. \& Renn, O. (1991). A novel approach to reducing uncertainty: the group Delphi. Technological Forecasting and Social Change 39(3), 253-263. Wisniewska, M. \& Szczepanska, K.A. (2014). Quality management frameworks implementation in Polish local governments. Total Quality Management \& Business Excellence 25 (3-4), 352-366.

Wisniewski, M. \& Olafsson, S. (2004). Developing Balanced Scorecards in local authorities: a comparison of experience. International Journal of Productivity and Performance Management 7, 602-610.

Woudenberg, F. (1991). An evaluation of Delphi. Technological Forecasting and Social Change 40, 131-150. 
Wu, H., Lin, Y. \& Chang, C. (2011). Performance evaluation of extension education centers in universities based on the balanced scorecard. Evaluation and Program Planning 34, 37-50. 
Table 1. Statistical Summary of Final Results.

\begin{tabular}{|c|c|c|c|c|c|c|c|c|c|}
\hline \multirow[t]{2}{*}{ Indicators } & \multicolumn{7}{|c|}{ Response Frequency (\%) } & \multirow{2}{*}{ Median } & \multirow{2}{*}{ Hierarchical Order } \\
\hline & 1 & 2 & 3 & 4 & 5 & 6 & 7 & & \\
\hline \multicolumn{10}{|c|}{ Financial } \\
\hline$F O 1 \_B B U$ & 45 & 35 & 20 & - & - & - & - & 2 & 1 \\
\hline FOI_MFR & 15 & 70 & 15 & - & - & - & - & 2 & 2 \\
\hline FO1_EEU & 25 & 25 & 50 & - & - & - & - & 2.5 & 3 \\
\hline$F O 2 \_D A B$ & 60 & 20 & 15 & 5 & - & - & - & 1 & 1 \\
\hline FO2_US & 20 & 40 & 20 & 20 & - & - & - & 2 & 2 \\
\hline FO2__MCR & 10 & 45 & 30 & 15 & - & - & - & 2 & 2 \\
\hline FO2_MRU & 5 & 20 & 40 & 35 & - & - & - & 3 & 3 \\
\hline FO3_SCF & 20 & 30 & 50 & - & - & - & - & 2.5 & 3 \\
\hline FO3_PCF & 25 & 50 & 25 & - & - & - & - & 2 & 2 \\
\hline$F O 3 \_E C F$ & 55 & 20 & 25 & - & - & - & - & 1 & 1 \\
\hline \multicolumn{10}{|c|}{ Learning and Growth } \\
\hline LDOI_UCOI & 10 & 35 & 40 & 15 & - & - & - & 3 & 3 \\
\hline LDO1_STVC & 5 & 45 & 45 & 5 & - & - & - & 2.5 & $2 / 3$ \\
\hline LDO1_CTI & 65 & 20 & 5 & 10 & - & - & - & 1 & 1 \\
\hline LDO1_DAM & 15 & 30 & 15 & 40 & - & - & - & 3 & 4 \\
\hline LDO2_CTACTIE & 20 & 75 & 5 & - & - & - & - & 2 & 2 \\
\hline LDO2_TAICC & 55 & 45 & 0 & - & - & - & - & 1 & 1 \\
\hline LDO2_ISTE & 15 & 10 & 75 & - & - & - & - & 3 & 3 \\
\hline LDO3_TPAPS & 60 & 40 & - & - & - & - & - & 1 & 1 \\
\hline$L D O \_3 \_T A D P S$ & 40 & 60 & - & - & - & - & - & 2 & 2 \\
\hline LDO4_DIA & 15 & 50 & 35 & - & - & - & - & 2 & 2 \\
\hline LDO4_PCIP & 65 & 20 & 15 & - & - & - & - & 1 & 1 \\
\hline LDO4_PIPM & 20 & 30 & 50 & - & - & - & - & 2.5 & 3 \\
\hline LDO5_ST & 25 & 35 & 40 & - & - & - & - & 2 & 3 \\
\hline$L D O 5 \_T W$ & 50 & 35 & 15 & - & - & - & - & 1.5 & 1 \\
\hline LDO5_SS & 25 & 50 & 20 & - & - & - & - & 2 & 2 \\
\hline \multicolumn{10}{|c|}{ Internal Process } \\
\hline IPOI_EAPM & 60 & 35 & 5 & - & - & - & - & 1 & 1 \\
\hline IPOI_CAEO & 40 & 55 & 5 & - & - & - & - & 2 & 2 \\
\hline IPOI_SVTE & 0 & 10 & 90 & - & - & - & - & 3 & 3 \\
\hline IPO2_CAPS & 70 & 30 & 0 & - & - & - & - & 1 & 1 \\
\hline IPO2_STPC & 20 & 50 & 30 & - & - & - & - & 2 & 2 \\
\hline IPO2_DPRAC & 10 & 40 & $\mathbf{5 0}$ & - & - & - & - & 2.5 & 3 \\
\hline IPO3_ATU & 0 & 35 & 45 & 20 & - & - & - & 3 & 3 \\
\hline IPO3_AA & 25 & 55 & 10 & 10 & - & - & - & 2 & 2 \\
\hline IPO3_JP & 65 & 30 & 5 & 0 & - & - & - & 1 & 1 \\
\hline IPO3_SC & 5 & 20 & 30 & 45 & - & - & - & 3 & 4 \\
\hline
\end{tabular}




\begin{tabular}{|c|c|c|c|c|c|c|c|c|c|}
\hline IPO4_APGA & 65 & 35 & - & - & - & - & - & 1 & 1 \\
\hline IPO4_PAGE & 35 & 65 & - & - & - & - & - & 2 & 2 \\
\hline IPO5_DMSP & 65 & 35 & - & - & - & - & - & 1 & 1 \\
\hline IPO5_EBE & 35 & 65 & - & - & - & - & - & 2 & 2 \\
\hline \multicolumn{10}{|c|}{ Customer } \\
\hline$C U \_J P U$ & 45 & 20 & 15 & 0 & 10 & 0 & 10 & 2 & 1 \\
\hline CU_FUSATR & 15 & 40 & 35 & 5 & 0 & 5 & 0 & 2 & 2 \\
\hline$C U_{-} F U S P G R$ & 0 & 15 & 15 & 35 & 25 & 10 & 0 & 4 & 4 \\
\hline CU_FUSMHRA & 0 & 15 & 35 & 25 & 10 & 15 & 0 & 3.5 & 3 \\
\hline CU_FUSARA & 0 & 5 & 25 & 5 & 10 & 40 & 15 & 6 & 6 \\
\hline CU_FUSPTS & 0 & 5 & 20 & 15 & 5 & 15 & 40 & 6 & 7 \\
\hline$C U \_G C U I$ & 15 & 25 & 15 & 5 & 25 & 10 & 5 & 3 & $2 / 5$ \\
\hline$C O E_{-} L D C C$ & 10 & 30 & 30 & 30 & - & - & - & 3 & $2 / 3 / 4$ \\
\hline COE_CCSSAT & 50 & 35 & 15 & 0 & - & - & - & 1.5 & 1 \\
\hline COE_CCSIC & 5 & 45 & 30 & 20 & - & - & - & 2.5 & 2 \\
\hline COE_GCCI & 15 & 20 & 45 & 20 & - & - & - & 3 & 3 \\
\hline CAE_CEAC & 30 & $\mathbf{5 0}$ & 15 & 5 & - & - & - & 2 & 2 \\
\hline CAE_EISCO & 20 & 45 & 30 & 5 & - & - & - & 2 & 2 \\
\hline CAE_PJTSSCO & 10 & 15 & 15 & 60 & - & - & - & 4 & 4 \\
\hline CAE_GCEAI & 30 & 25 & 35 & 10 & - & - & - & 2 & 3 \\
\hline CAS_CTA & 5 & 35 & 60 & - & - & - & - & 3 & 3 \\
\hline CAS_CCUAS & 45 & 50 & 5 & - & - & - & - & 2 & 2 \\
\hline CAS_GCTUAI & 40 & 40 & 20 & - & - & - & - & 2 & $1 / 2$ \\
\hline CPC_OIP & 20 & 20 & 10 & 50 & - & - & - & 3.5 & 4 \\
\hline CPC_JSCMR & 15 & 35 & 45 & 5 & - & - & - & 2.5 & 3 \\
\hline CPC_JSCOO & 60 & 25 & 15 & 0 & - & - & - & 1 & 1 \\
\hline CPC_GCPI & 25 & 35 & 25 & 15 & - & - & - & 2 & 2 \\
\hline
\end{tabular}


Table 2. Consensus criterion: overall results.

\begin{tabular}{|c|c|c|c|}
\cline { 2 - 3 } \multicolumn{1}{c|}{ Perspective } & \multicolumn{2}{c|}{ Dispersal } & \multirow{2}{*}{$\begin{array}{c}\text { Variation in the Degree of } \\
\text { Consensus }\end{array}$} \\
\cline { 2 - 4 } & First Round & Second Round & 0.316 \\
\hline Financial & 0.911 & 0.595 & 0.339 \\
\hline Learning and Growth & 0.914 & 0.574 & 0.351 \\
\hline Internal Process & 0.926 & 0.576 & 0.412 \\
\hline Customer & 0.949 & 0.536 & 0.355 \\
\hline Global & 0.925 & 0.570 & 0 \\
\hline
\end{tabular}


Table 3. Stability criteria.

\begin{tabular}{|c|c|c|c|c|c|c|c|}
\hline \multirow{2}{*}{ Perspective } & \multirow{2}{*}{$\begin{array}{l}\text { Strategic } \\
\text { Objective }\end{array}$} & \multicolumn{6}{|c|}{ Stability } \\
\hline & & \multicolumn{2}{|c|}{ Qualitative Group } & \multicolumn{2}{|c|}{ Quantitative Group } & \multicolumn{2}{|c|}{ Absolute Individual } \\
\hline \multirow{3}{*}{ FINANCIAL } & FO1 & $53.33 \%$ & \multirow{5}{*}{$46.67 \%$} & $100.00 \%$ & \multirow{5}{*}{$95.00 \%$} & 11 & \multirow{4}{*}{$9(46.67 \%)$} \\
\hline & $\mathrm{FO} 2$ & $40.00 \%$ & & $90.00 \%$ & & 8 & \\
\hline & FO3 & - & & - & & - & \\
\hline \multirow{5}{*}{$\begin{array}{l}\text { LEARNING AND } \\
\text { GROWTH }\end{array}$} & LDO1 & $43.75 \%$ & & $87.50 \%$ & & 8 & \\
\hline & $\mathrm{LDO} 2$ & $60.00 \%$ & & $95.00 \%$ & & 12 & \multirow{6}{*}{$9(44.31 \%)$} \\
\hline & LDO3 & - & \multirow{5}{*}{$46.25 \%$} & - & \multirow{5}{*}{$91.25 \%$} & - & \\
\hline & LDO4 & - & & - & & - & \\
\hline & LDO5 & $35.00 \%$ & & $91.25 \%$ & & 7 & \\
\hline \multirow{5}{*}{$\begin{array}{l}\text { INTERNAL } \\
\text { PROCESS }\end{array}$} & IPO1 & - & & - & & & \\
\hline & IPO2 & $40.00 \%$ & & $93.33 \%$ & & 8 & \\
\hline & IPO3 & $37.50 \%$ & \multirow{4}{*}{$38.75 \%$} & $86.25 \%$ & \multirow{4}{*}{$89.79 \%$} & 7 & \multirow{4}{*}{$8(38.31 \%)$} \\
\hline & IPO4 & - & & - & & - & \\
\hline & IPO5 & - & & - & & - & \\
\hline \multirow{5}{*}{ CUSTOMER } & $\mathrm{CU}$ & $34.29 \%$ & & $78.57 \%$ & & 7 & \\
\hline & $\mathrm{COE}$ & $40.00 \%$ & \multirow{4}{*}{$42.94 \%$} & $95.00 \%$ & \multirow{4}{*}{$88.38 \%$} & 8 & \multirow{4}{*}{$8(42.19 \%)$} \\
\hline & CAE & $35.00 \%$ & & $91.25 \%$ & & 7 & \\
\hline & CAS & $56.67 \%$ & & $98.33 \%$ & & 11 & \\
\hline & $\mathrm{CPC}$ & $48.75 \%$ & & $78.75 \%$ & & 10 & \\
\hline
\end{tabular}


Table 4. Balanced Scorecard for PVTCs.

\begin{tabular}{|c|c|}
\hline $\begin{array}{l}\text { FINANCIAL PERSPECTIVE } \\
\text { (3 indicators) }\end{array}$ & $\begin{array}{l}\text { LEARNING AND GROWTH PERSPECTIVE } \\
\text { (5 indicators) }\end{array}$ \\
\hline $\begin{array}{l}\text { Budget Being Used } \\
\text { Distributing Annual Budget } \\
\text { Executing Complementary Financing }\end{array}$ & $\begin{array}{l}\text { Centers' Technological Infrastructure } \\
\text { Training Actions Integrated into Centers coordinated } \\
\text { by CTIER } \\
\text { Training Proposals In the Production Sector } \\
\text { Participation in Curricular Innovation Projects } \\
\text { Teamwork }\end{array}$ \\
\hline $\begin{array}{l}\text { INTERNAL PROCESS PERSPECTIVE } \\
\text { (5 indicators) }\end{array}$ & $\begin{array}{l}\text { CUSTOMER PERSPECTIVE } \\
\text { (5 indicators) }\end{array}$ \\
\hline $\begin{array}{l}\text { European Academic- Professionalizing Mobilities } \\
\text { Collaboration Agreements with the Production } \\
\text { Sector } \\
\text { Job Placement for Users } \\
\text { Academic-Professional Guidance Actions } \\
\text { Developing a Management System Per Process }\end{array}$ & $\begin{array}{l}\text { Former Users' Satisfaction with Academic Training } \\
\text { Received } \\
\text { Collaborating Companies' Satisfaction with Students' } \\
\text { Academic Training } \\
\text { Claims received by the Education Administration } \\
\text { which the Center depends on } \\
\text { Collaboration Center-Trade Union Associations' } \\
\text { Satisfaction } \\
\text { Job Satisfaction with the Center's Organization and } \\
\text { Operation }\end{array}$ \\
\hline
\end{tabular}


Figure 1. A Strategic Map of a PVTC. Black indicates an indirect relation among several objectives; gray and white denote a direct cause and effect between two objectives.

Figure 2. The Strategic Objectives of PVTCs.

Figure 3. Indicators proposed for the BSC of a PVTC. 